\title{
Opinion
}

Copyright (C) All rights are reserved by David O Draper

\section{SAM, A New Portable Long Duration Ultrasound Device}

\author{
David 0 Draper* \\ Brigham Young University, USA
}

*Corresponding author: David O Draper, Professor of athletic training and sports medicine, Brigham Young University, Provo, Utah, USA

Received Date: December 07, 2018

Published Date: December 13, 2018

\section{Opinion}

The SAM (sustained acoustic medicine) ultrasound device is a small, portable device that delivers over 9000 Joules of energy when worn for 4 hours. This has been shown to decease pain in knee osteoarthritis, trapezius myofascial pain, low back pain with a herniated disk, tendinopathy of elbow and ankle, and shoulder pain. The following is a case of a construction worker who was limited in his work from a sore shoulder. [Figure 1]

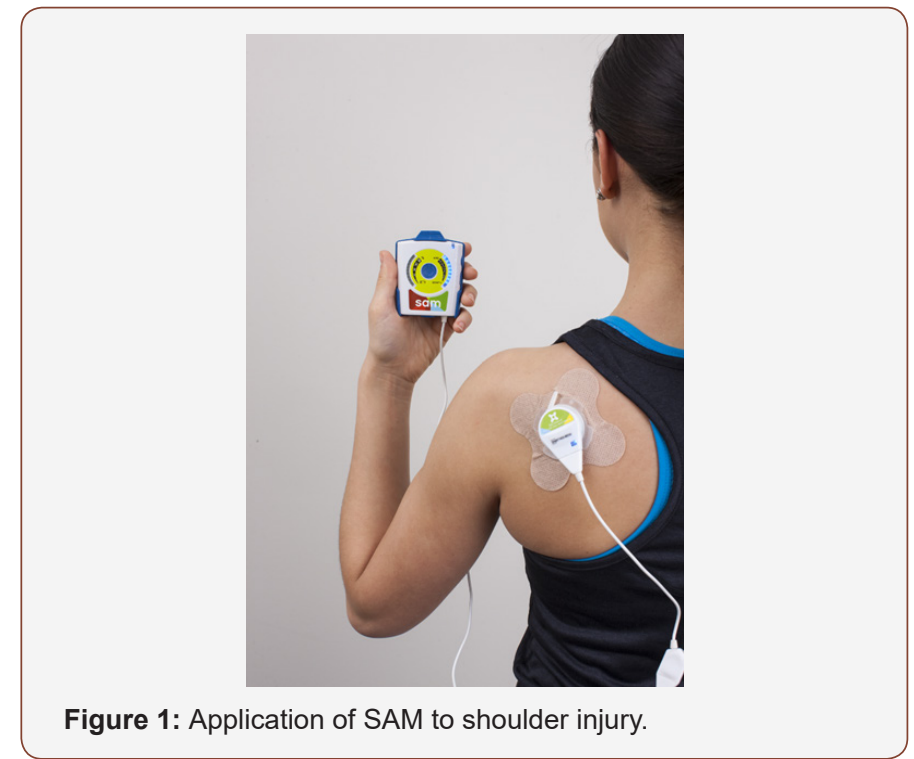

Patient: Wesley W. Kansas

Diagnosis: Right shoulder pain from overuse.

\section{Testimonial}

My quality of life prior to using the SAM was "A slow recovery with loss of motion." There were lots of things that I couldn't do, including reach for things up high. I hurt most of the time.

My initial pain level was a 7-8 on a scale of $0=$ no pain and 10 = worst pain possible. After using SAM for 2-3 weeks my pain level was 4-5.

After using SAM, I regained more motion in my shoulder. It gets better as time goes on by using the SAM".

"I feel that if I would have had this unit at the time of my first surgery I would be at a better level with my shoulder. I think that SAM is something everyone needs to use after knee-shoulder-elbow or even back surgery."

\section{Acknowledgement}

None.

\section{Conflict of Interest}

No Conflict of Interest. 